\title{
MOTIVATING STUDY BEFORE CLASSES ON FLIPPED LEARNING
}

\author{
L. Descalço', P. Carvalho', P. Oliveira' \\ 'University of Aveiro (PORTUGAL)
}

\begin{abstract}
For the flipped learning environment to be effective, it is essential that students use the learning materials before the classes, where they are supposed to practice, collaborating with colleagues with the help and guidance of the teacher.

Students can easily get lost and unmotivated if the teacher simply gives them the learning material for studying before the classes. There is a need for some level of guidance and orientation in this autonomous learning for many students or they will go to the classes without having done the previous work required.

We have developed a computer system with the main goal of motivating and guiding students to do this work before the classes. The computer system implements a Bayesian student model together with a learning trajectories model and makes use of a parameterized question generator, without any limitations on the parameterization we have also helped to develop. In practice, the computer system for learning presents the materials in an appealing and appropriate way, individually according to each student progress, including videos and other materials. Students can answer some of the many existing questions, generated among many parameterized templates, see detailed solutions of questions, also generated, and finally obtain a feedback about their progress in the learning contents required to next class.
\end{abstract}

In the first semester of academic year 2017/2018, we have used our computer system with students in some of the topics of a course about calculus with several variables. The system keeps track of all activity and allows us to investigate student behaviour during the semester.

We present an analysis of the system usage data on the topics in the experience comparing to those on traditional teaching, and relate with the results in final assessment, with the main goal of investigating the effectiveness of the use of this kind of computer systems in a flipped learning environment for motivating and guiding autonomous work before the classes.

Keywords: Motivation, calculus, flipped learning.

\section{INTRODUCTION}

Flipped learning environments are getting popular and make sense in our age of information were the main role of the teacher is no longer to present information (see [1]). In a flipped learning environment, students learn by themselves at their own pace using appropriate material, preferentially prepared by their teachers and then in the classes they exercise with the help of teachers and colleagues. We observe that many students do not attend traditional classes, if they are not obligatory or, if they attend the classes, smartphones and other electronic devices easily distract them. There is a clear need for change and one possibility is to use, at least partially, flipped learning.

Computers and smartphones can be used for learning, and in particular, videos are as effective as lectures, at least in less complicated subjects (see [2,3,4]). We have proposed in [5] an extension of a computer system for use in a flipped learning environment adding, among other elements, introductory videos. In this article, we present some usage data from a Web application, named SIACUA, implemented by us (see [6]), and now expanded including other Learning Objects (LOs) containing introductory videos along with other contents. This expansion is based on the extension proposed in [5] and we have used it with students on some topics taught with the flipped learning method. The main objective of this work is to compare the results in topics in flipped learning using this Web application and topics in traditional teaching without using the Web application.

As we stated in [5], one problem with flipped learning is that students may not prepare themselves for the classes using the proposed material supplied. Our approach to try to reduce this problem is to 
provide the material through a very clear and simple Web application capable of providing useful feedback about the study progress. For that, our application uses Bayesian networks to compute the feedback it provides to students. Additionally, we deal with this problem by doing assessment in the classes using another computer system, PmatE (see [7]). Although we think that, a high number of assessments is not the ideal educational procedure and it would be preferable that students had an intrinsic motivation, we observe that many students only care about studying mathematics when they will be immediately evaluated. Hence, to provide good material with feedback and assessment in the classes seems to be the most appropriate approach in our conditions.

The experience we describe was done with students of Industrial Management Engineering on the University of Aveiro, Portugal. Our sample is composed by all the 24 students in this course, on the academic year 2017/2018 that submitted themselves to assessment during the classes. The remaining students were evaluated by final exam and were not considered in this experience since the assessment and conditions are of different nature. The subject in observation is Calculus with Several Variables; we designate the course here simply by "Calculus".

\section{METHODOLOGY}

We have selected two topics of the course, and to one of them we applied flipped learning while in the other we maintained traditional learning. These topics are: (i) limits, continuity and differentiability of functions of several variables and (ii) partial differential equations. For the first topic students were advised to study previously using our computer system SIACUA and then they exercised in the classes. Topic (ii) was introduced in the classes with examples of solving of differential equations and students practiced after classes with the proposed exercises.

The material for studying the topic (i) is available in SIACUA in the following way: (1) material for remembering previous contents required for this specific topic, like limits of functions on one variable.

(2) Material for a first introduction to the topic, including short videos with simple and clear examples.

(3) References for the complete study, in particular from the books we published specifically for studying this course. (4) A progress bar computed by the Bayesian network for each student, taking into account all evidences of knowledge supplied by the student. This progress bar is the most interesting part of the system: a student can click it to access all questions generated by parametrized templates produced with system MEGUA (see $[8,9]$ ). The progress will increase or decrease taking into account the new evidences of knowledge supplied. The knowledge beliefs are propagated through the entire graph representing the concepts of the course according to a user model (see [10]).

The system aims to simulate what teachers normally do when teach something. First, we try to understand what the students already know and help them to remember what is relevant for what we are going to teach (1). Then we introduce the subject (2) and finally give references (3) (see buttons 1 , 2 and 3 in Figure 1). In addition, and the most important, we are available to provide relevant feedback about their new knowledge (4) what corresponds to the red and blue progress bars in Figure 1. This figure presents the part of SIACUA interface corresponding to topic (i) in flipped learning.

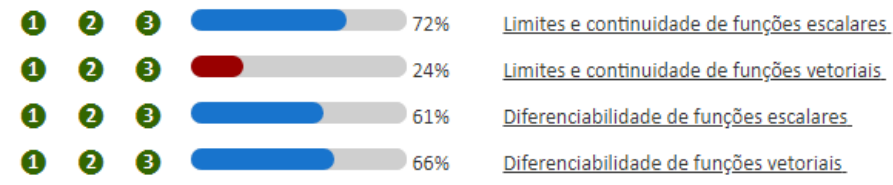

Figure 1. Studying with SIACUA

Together with the progress bar, students see three elements before the bar that can be marked several different ways. The elements are colored in grey if not available, in green if available, can appear as visited or not and can be marked by the student as complete. This is a simple way for supporting the students to keep track of their own progress in their study in flipped learning and have feedback about their preparation level for the following class.

The assessment of students in the Calculus course consists of two main tests with $80 \%$ weight in the student's final mark together with several mini-tests with the remaining $20 \%$ weight. We compare the results in a question (Q1) in main test 1, about topic (i) in flipped learning with the results in a question (Q2) of main test 2, about topic (ii) in conventional learning. Taking into account the kind of students in this course, the work in class and the given material, the two questions were considered of equivalent difficulty level by three teachers of this course. We note that this is subjective and sometimes 
teacher's previsions do not correspond to the results obtained by students. However, we consider, what is also subjective, that by the nature of these particular questions and their answers, the difficulty level is in fact similar. We present the two questions in Figure 2.

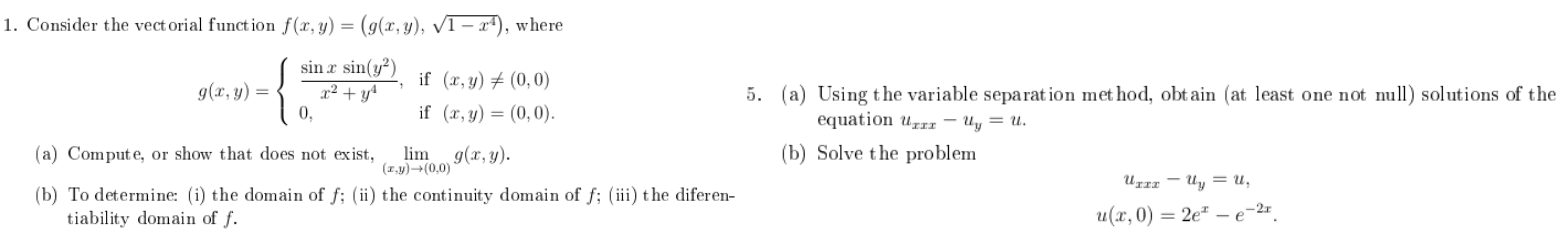

Figure 2. The two questions observed on the assessment (Q1) and (Q2)

\section{DISCUSSION AND RESULTS}

We are interested to know if the student's results in the topic in flipped classroom are similar or not to the results in the topic in traditional learning and we want to test if they are effectively studying using our computer system. Moreover, we want to know if the question (Q1) in flipped learning has similar results for all students or if some students benefit more than others with this approach, compared with traditional learning. Each of the following two sections addresses one of these questions.

\subsection{Flipped learning vs conventional}

In Figure 3 we present the student's marks on both questions, (Q1), referring to the topic in flipped learning and (Q2) about topic in traditional learning.

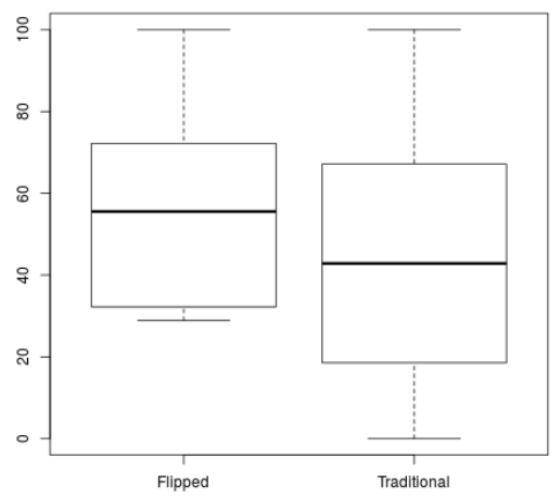

Figure 3. Flipped vs traditional learning marks

It is clear in the boxplots, that the results on (Q1) look better than the results in (Q2). Nevertheless, we observe that 14 students have better results in (Q1) but the other 10 have worst results. Not assuming normality in this small sample, comparing the data with a Wilcoxon signed rank test with significance level 0,05 we get $p$-value 0,2 . Hence, there is no clear evidence of advantage of flipped learning compared with traditional learning in our particular conditions.

\subsection{Study with Web application SIACUA}

We have collected data form SIACUA in 3 different dates: (A) before the class where topic (i) was practiced; (B) before a mini-test about topic (i) after the class; (C) before main test 1; (D) before main test 2 . From all 24 students in the experience, only 13 have effectively used the system until date $(A)$, 19 until dates (B) and (C), and 23 until date (D). This is clearly below our expectations. Nevertheless, it is important data showing we cannot assume all students study before the classes, even if we give them the material this way, in the form of a web application like SIACUA, with immediate feedback.

Table 1 presents some data about system usage until these three dates, by the 24 students. First row contains average and standard deviation for the number of actions (logins, selecting questions, 
answers, etc.) in the four dates. Row 2 refers to the number of logins, from PC and mobile devices combined. Row 3 concerns with the number of visits to the new Learning Objects (LOs) with videos on the new expansion of SIACUA. We note that this application is under construction and we only have theses LOs in topic (i) and a few others. Finally, row 4 has the numbers for answers to the parameterized multiple-choice questions available. We note that many students see the questions and do not answer them. In fact, the logged total number of questions seen by the 24 students until date (D) is 15063 while they have answered only 5394 questions.

Table 1. System usage

(A)

(B)

(C)

(D)

\begin{tabular}{|l|c|c|c|c|}
\hline Actions (Average/Std. Dev.) & $49 \mid 96$ & $306 \mid 252$ & 982 | 546 & 1537 | 786 \\
\hline Logins (Average/Std. Dev.) & $2 \mid 4$ & $10 \mid 8$ & $30 \mid 16$ & $44 \mid 21$ \\
\hline Visits to LOs (Average/Std. Dev.) & $5 \mid 8$ & $17 \mid 14$ & $49 \mid 31$ & $51 \mid 30$ \\
\hline Answers to questions (Average/Std. Dev.) & $6 \mid 14$ & $51 \mid 53$ & $154 \mid 106$ & $224 \mid 140$ \\
\hline
\end{tabular}

Table 2 presents, for the 24 students in the experience, the mean and the median of results in question (Q1) and of final mark on Calculus, for students that have used compared with those that have not used the system until each of the four dates. We can see that system usage has a positive effect on the results in Calculus although it has no visible effect on the results in question (Q1).

Table 2. Results and system usage

$\begin{array}{llll}\text { (A) } & \text { (B) } & \text { (C) } & \text { (D) }\end{array}$

\begin{tabular}{|l|l|l|l|l|}
\hline Mean result on Q1 for students that have used the system & 54,7 & 55,0 & 55,0 & 55,0 \\
\hline Mean result on Q1 for students that have not used the system & 55,4 & 55,6 & 55,6 & 55,6 \\
\hline Mean result in Calculus for students that have used the system & 72,3 & 69,6 & 68,5 & 68,5 \\
\hline Mean result in Calculus for students that have not used the system & 62,7 & 65,9 & 55,0 & 55 \\
\hline Median result in Q1 for students that have used the system & 51,1 & 55,6 & 51,1 & 55,6 \\
\hline Median result in Q1 for students that have not used the system & 55,6 & 55,6 & 55,6 & 55,6 \\
\hline Median result in Calculus for students that have used the system & 70,0 & 65,0 & 65,0 & 65 \\
\hline Median result in Calculus for students that not have used the system & 65,0 & 55,0 & 55,0 & 55 \\
\hline
\end{tabular}

We checked if there are correlations between the number of actions, logins, visits to LOs and the marks in (Q1) and final mark in Calculus. In table 3 we can see that there is a weak correlation between the final results and system usage on some dates and there is no correlation between the results in question (Q1) and system usage. In fact, we were not expecting to find any correlation because the system is for introduction to the topics and references for a complete study 
complemented with the classes. Moreover, 11 of the 24 students did not use the system before the class.

Table 3. Pearson correlation: system usage / student's results

(A)

(B)

(C)

(D)

\begin{tabular}{|l|r|r|r|c|}
\hline Actions / Calculus mark & 0,396 & 0,261 & 0,337 & 0,252 \\
\hline Actions / mark Q1 & 0,274 & 0,153 & $-0,068$ & $-0,146$ \\
\hline Number of logins / Calculus mark & 0,296 & 0,246 & 0,268 & 0,197 \\
\hline Number of logins / mark Q1 & 0,147 & 0,115 & $-0,066$ & $-0,077$ \\
\hline Visits LOs / Calculus Mark & 0,387 & 0,489 & 0,200 & 0,235 \\
\hline Visits LOs / Mark Q1 & 0,181 & 0,103 & $-0,125$ & $-0,158$ \\
\hline
\end{tabular}

\section{CONCLUSIONS AND FUTURE WORK}

From our study, our most important conclusion is that it is very difficult to convince students to do the necessary work before the classes unless we include at least some short assessment in inverted classes. If may even be preferable to do the assessment in the beginning of the class to avoid that some students don't do the previous study and expect to learn only in the class, what may occur if the assessment is done for example in the end of the class.

Flipped learning seems to be better for some students and worst for others, as suggested by the results in question (Q1), compared with the results in question (Q2). We can observe that in the traditional classes: some students can follow the class and participate while others are constantly distracted. For the students not able to focus on the class, flipped learning may be more suitable. Hence, in our conditions, where many students from engineering do not have intrinsic motivation for mathematics, it is not clear that the advantages of flipped learning overcome the inconvenient. It is however clear the importance of having a system to log student's activity, avoiding the wrong assumption that they all work before the classes.

Another conclusion is that students in fact work using our system. The regular study during the semester is related with success in the course (see [11]) and so we try to provide conditions to keep them working. There is a consistent good feedback from students about system SIACUA, considering it very useful for studying. One positive feature pointed out by students is the detailed solutions and answers for problems available in the system, which can somehow justify the higher number of seen questions versus the number of answered questions; another one is the feedback it provides (see $[12,13,14])$. It is natural that our students prefer to learn using also their computers and mobile phones than using only traditional printed materials. Therefore, we think the development of a specific Web application and materials for students, by their teachers, is an important gain.

It is our sense that this study has some weaknesses, namely the difficulty level of the questions being the same is subjective, the topics being quite different, and so each topic can be easier for some students and more difficult for others, and finally it would be better to have a larger sample. Nevertheless, we have common sense conclusions confirmed in these particular conditions.

We plan to continue our work in two directions: continuing the study of the best conditions to perform and compare flipped learning, other active learning strategies and traditional learning, and continuing the development of our computer system to improve feedback and in order to guide students among the learning material and topics. 


\section{ACKNOWLEDGEMENTS}

This work was supported in part by the Portuguese Foundation for Science and Technology (FCTFundação para a Ciência e a Tecnologia), through CIDMA - Center for Research and Development in Mathematics and Applications, within project UID/MAT/04106/2013.

\section{REFERENCES}

[1] A. Prieto Martin, Flipped Learning. Aplicar el Modelo Aprendizaje Inverso (Universitaria), Narcea Ediciones, 2017.

[2] P.A. Cohen, B. J. Ebeling and J. A. Kulik, "A meta-analysis of outcome studies of visual-based instruction”, Educational Technology Research and Development, vol. 29(1), pp. 26-36, 1981.

[3] B.J. McNeil, $A$ Meta-analysis of interactive video instruction: $A 10$ year review of achievement effects, Doctoral Dissertation, University of Idaho, USA, 1989.

[4] D. Zhang, L. Zhou, R. O. Briggs and J. F. Nunamaker, "Instructional video in e-learning: Assessing the impact of interactive video on learning effectiveness", Information \& Management, vol. 43(1), 15-27, 2006.

[5] L. Descalço, A. do Canto Filho and J. Valdeni de Lima, "Learning Trajectories with Bayesian student model for autonomous study in flipped learning", Proceedings of EDULEARN17 Conference, IATED, 564-569, Spain, 2017.

[6] SIACUA. Accessed 4 May 2018. Retrieved from http://siacua.web.ua.pt/

[7] Projeto Matemática Ensino (PmatE), Accessed 19 March, 2018. Retrieved from https://pmate.ua.pt/

[8] MEGUA. Accessed 4 May 2018. Retrieved from http://cms.ua.pt/megua/

[9] P. Cruz, P. Oliveira and D. Seabra, "Exercise templates with Sage", Tbilisi Mathematical Journal, vol. 5(2), 37-44, 2012.

[10] E. Millán, L. Descalço, G. Castillo, P. Oliveira and S. Diogo, "Using Bayesian networks to improve knowledge assessment", Computers and Education, vol. 60(1), pp. 436-447, 2013.

[11] A. Gonçalves, A. Tomé and L. Descalço, "Predicting Student Performance with Data from an Interactive Learning System" (http://ria.ua.pt/handle/10773/16628), RecPad 2016, Universidade de Aveiro, 35-37, 2016.

[12] L. Descalço and P. Carvalho, "Using Parameterized Calculus Questions for Learning and Assessment" (http://ieeexplore.ieee.org/xpl/mostRecentlssue.jsp?punumber=7152443), Atas da 10ª Conferência Ibérica de Sistemas e Tecnologias de Informação, 710-714, Águeda, Portugal, 2015.

[13] L. Descalço, P. Carvalho, J. P. Cruz, P. Oliveira and D. Seabra, "Using Bayesian Networks and Parametrized Questions in Independent Study", Proceedings of EDULEARN15 Conference, IATED, 3361-3368, Spain, 2015.

[14] L. Descalço, Paula Carvalho, J. P. Cruz, Paula Oliveira and D. Seabra. "Computer-assisted independent study in multivariate calculus" (http://arxiv.org/abs/1507.05049), Proceedings of EDULEARN15 Conference, IATED, 3352-3360, Spain, 2015. 